\title{
Augmented Reality (AR) Generated Value-in-Use Experiences: Literature Review and Analysis
}

\author{
Riham Adel, PhD \\ Associate Professor \\ College of Management \& Technology \\ Arab Academy for Science, \\ Technology and Maritime Transport, Egypt \\ E-mail : rehamadel@aast.edu
}

\begin{abstract}
Augmented Reality (AR) research has sparked both academia and practice interest. However, despite the increasing interest to study this emergent topic, till now the growing body of knowledge is mainly from engineering and computer science disciplines. The aim of this study is to conduct a systematic literature review to identify, evaluate and synthesize (AR) emergent themes from business management publications in the last years. Hence, contribute to the literature with evidence-based results about the existing research progress, and classify into clusters with multidimensional interrelationships to help researchers build up on these findings and expand (AR) research from business standpoint. The study is exploratory and qualitative in nature; a structured hybrid-narrative review method is used to extract unstructured data within articles. Thus, discover relevant patterns, uncover hidden thematic clusters, relationships, and identify multidimensionality of dominant concepts from the existing (AR) business literature. It was evident from the stream of research, that most of researchers' have a clear interest in exploring the interactive nature of Augmented Reality $(A R)$ as new digital technology and defining its experiential characteristics with a hierarchical set of dimensions that will affect customers' perceptions of service operations. Hence, in line with these findings, and grounded on the service literature body of knowledge, Augmented Reality can be defined as: "smart service based technology that generate value-in-use experiences".
\end{abstract}

Keywords: Augmented Reality (AR); Smart Service; Value-in-use; Experience.

\section{Introduction}

Disruptive technologies evolving in recent years have showed instant implications in service industries. Yet in the newly digitalised era, service innovations are advancing towards smartness, whereas interactions are more intelligent, thus improving the potentials of value co-creation which is considered the central tenet of service-dominant (S-D) logic.

S-D logic initially focuses on the active role of customers' engagement in co-creation throughout integrating their personal resources (i.e. operant resources) with those of the firm (i.e. operand resources) to generate value-in-use, which is consequently determined by the customer's evaluation of experience during consumption. Furthermore, it is discussed that S-D logic can be complemented with virtual-based logic that is enabled by new technologies to create value from simple information sharing to big data analytics, thus support service network actors in recognising value (Lindhult et al., 2018; Bani-Hani et al., 2018; Buhalis et al., 2019).

* This article was submitted in November 2021, and accepted for publishing in December 2021.

(c) Arab Administrative Development Organization- League of Arab States, 2024, pp 227-241، D DOI: 10.21608/aja.2021.108470.1182 
Obviously the rapid technological progressions have given organisations numerous opportunities to rethink new alternatives for interacting and engaging with customers. Shankar et al. (2021) refer to technologies (i.e. internet of things; artificial intelligence; virtual and augmented reality; smart mirrors; face recognition; chatbots...etc.) by "Customer-Facing Technologies".

Such technologies enhance the value creation and radically transform consumers' experience throughout facilitating engagement during customers' decision making journey. It is acknowledged that these technological transformations have an impact in almost all industries, shifting organisations' attention towards smart operations that are characterised by real-time, instant interactive connectivity with value-chain actors. Consequently, enhance information communication flow, digitalised solutions, and personalization of offerings to create an experiential value consisting of cognitive, emotional, and social dimensions (Hoyer et al., 2020).

Augmented Reality (AR) is viewed as one of the cutting-edge technological innovations, representing Mixed Reality (MR) that can be categorised into two types marker-based and marker less. AR is a blend between virtual and real environments, combining elements from both settings that interact simultaneously in real-time. AR technologies can be utilised through devices such as laptops, smartphones, head-mounted display, and smart glasses to display layered information (i.e. rich media content that is communicated assimilating real-time telepresence) resulting from users' interaction with their current surroundings, thus immerse them into virtual and pleasurable experiences (Roxo and Brito, 2018; Yussof et al., 2019).

AR popularity grew due to its ability to virtually visualize objects/contexts throughout augmentation, thus expand the possibilities offered to industries by combining the physical and virtual worlds effectively, whereas traditional and digital environments co-exist to enable virtual real-time information display, products' demonstrations, pre-purchase assessments to facilitate customers' decision making and give them feelings of entertainment (Rese, Baier, Geyer-schulz, et al., 2017).

The more users' expectations and interactions in AR environment are congruent, the higher users are immersed in AR experiences. Therefore, chances are high that AR experience is perceived realistic when users have higher perceptions and feelings of physical presence inside the AR environment. It is argued that the three main features respectively (1) feelings of presence; (2) realism level; and (3) reality degree can be considered the main indicators of AR quality experiences (Cipresso et al., 2018).

AR technologies have been applied widely in many fields including industrial, medical, tourism, retail, education, media and entertainment (Watson et al., 2020). The pervasive use of such revolutionary technologies pave the way for companies to shift from traditional services into smart ones. Leading companies are increasingly embracing the use of AR technologies that offer a dynamic way to interact with consumers. Services are co-created with customers to provide them with interactive and novel experience simulation beyond physical environment (Caboni and Hagberg, 2019). Hence, it is expected an increase of $\$ 85$ billion in AR market size by 2025 (Kowalczuk et al., 2021).

Despite the fact that AR offers customers with more informative and enjoyable consumption experiences throughout setting a frontline interface that displays virtual content which is customised based on each user's personal information. Yet, it is argued that augmentation quality is indispensable to the establishment of positive users' experience which is measured by the perceived value gained from using AR. On the other hand, several researchers have stressed the importance of users' privacy control. They assert that the extent of information users is willing to share is dependent on the value they expect to achieve. Accordingly, it is claimed that AR technologies enabling users to have control over the access to their personal information will generate more engaging experiences, lower their levels of anxiety and perceived risks which enhance the customers' quality of experience at time of the purchase. Consequently, it is determined that positive AR experiences will lead to customers' satisfaction and willingness to purchase (Hilken et al., 2017; Poushneh and Vasquez-parraga, 2017; Watson et al., 2018; Poushneh, 2018; Perannagari and Chakrabarti, 2019). 
Therefore, AR should be observed from a quality-experience driven lens, rather than technology-driven one. AR quality of experience is influenced by virtual content that is perceived by the users who directly experience augmentation within a particular setting or application (Scholz and Smith, 2016). Thus, AR creates digital affordance that drives consumers' experiences, and maximizes consumers' engagement by involving them into quality interactive media experiences. These experiences of situated cognition can be classified into: (1) embedded which is defined in terms of information integration within personal context in real-time to evaluate products/services; (2) embodied which refers to simulated physical interactions with products/services which improve customers' ability to evaluate an offering; (3) distributive which is an extended experience where customers share their experiences with peers to support them in products/service evaluation. It is noted that AR supplements reality with an enhanced view of physical environment by providing customers with embedded, embodied, and extended consumption experiences that are adaptive with their needs and tastes. Accordingly, it can be concluded that AR value propositions consist of digital content vividness, interaction, personalisation and connectivity (Hilken et al., 2018; Chylinski et al., 2020).

Although AR is the latest emergent technology mostly investigated in academia in the last few years, but it is still considered in its nascent stages. Most of the existing AR publications are dominated by computer science research studying technological and engineering aspects disregarding business perspective and service operations aspects. Furthermore, it was noted that the current AR body of knowledge lacks integration between different disciplines which can help in developing more generalised models and measurement scales. Whilist, several studies are available to explain AR technologies' acceptance and behaviors adoption models, but still there is an absence of academic research on how AR technology can transform service operations. Therefore, further review is required to get a better understanding of AR value-in-use related aspects and new experiences resulting from using AR technologies (Rese et al., 2017; Scholz and Du, 2018; Roxo and Brito, 2018; Caboni and Hagberg, 2019; Perannagari and Chakrabarti, 2019; Park and Stangl, 2020; Wedel et al., 2020; Hoyer et al., 2020).

Accordingly, the purpose of this paper is to review the progress of business literature in Augmented Reality (AR) to examine the main research streams discussed to date. Furthermore, discuss its effect on service operations' transformation. The remainder of the paper is structured as follows: the next sections are presenting, First the systematic literature review methods. Second, elaborating findings with respect to three main characteristics that distinguish Augmented Reality (AR) including: smart service technology, value-in-use, and generated experiences. Third, examining how Augmented Reality (AR) is transforming of service operations. The final section discusses the theoretical and practical implications of the study, with recommendations for future research to be conducted.

\section{Systematic Literature Review}

The aim of this section is to pinpoint the research progress related to the emergent topic Augmented Reality (AR) within business research area. A structured hybrid-narrative review is used to give an in-depth insight on existing body of knowledge. Therefore, it is essential to search and select the relevant studies for a comprehensive synthesis of literature (Cavalinhos et al., 2021).

This study was conducted in May 2021 using Scopus and Web of Science Core Collection databases. Scopus and WoS are acknowledged to be principal academic search systems that provide access to multiple databases simultaneously. Both databases meet systematic review quality requirements such as broad scope, multidisciplinary coverage, available record types and effective query-based search that promote support for Boolean searching with different options for filtering content (Gusenbauer and Haddaway, 2020).

\section{Searching and Screening Procedure}

An initial search to scope peer-reviewed articles from high-impact journals with title and topics using the Boolean operators (AND); (OR) to identify articles addressing the concept of augmented reality experience 
quality. The papers were searched using the following title "Augmented Reality Quality" (OR) "Augmented Reality Experience" (OR) "Augmented Reality Valuein-Use". Then linking with the search strings keywords for topics including "virtual quality" (AND) "service quality" (AND) "virtual experience" (AND) "experience quality" (OR) "quality of experience" (AND) "service dominant logic" (OR) "co-creation".

The preliminary search results from WoS returned 8,686 titles and 466 titles from Scopus. Yet, the results were refined to include only English, peer-reviewed full-text articles published in academic journals in business and management research area across all years (See Table 1). Guided by the inclusion criteria, the final search results displayed 27 titles from WoS and 23 titles from Scopus published from 2012 to 2021.

Table 1 Search Results Inclusion Criteria

\begin{tabular}{|c|c|}
\hline $\begin{array}{l}\text { Databases } \\
\text { Topic }\end{array}$ & $\begin{array}{c}\text { Web of Science (WoS) Core Collection; Scopus } \\
\text { Augmented Reality }\end{array}$ \\
\hline $\begin{array}{l}\text { Search Strings } \\
\text { (title, keywords) }\end{array}$ & $\begin{array}{l}\text { "Augmented Reality Quality"; "Augmented } \\
\text { Reality Experience"; "Augmented Reality Val- } \\
\text { ue-in-Use"; "virtual quality" (AND) "service } \\
\text { quality"; "virtual experience"; "experience } \\
\text { quality"; "quality of experience"; "service } \\
\text { dominant logic"; "co-creation". }\end{array}$ \\
\hline Indexes & $\begin{array}{l}\text { SCI-EXPANDED, SSCI, A\&HCl, CPCI-S, CP- } \\
\text { Cl-SSH, BKCl-S, BKCl-SSH, ESCI. }\end{array}$ \\
\hline Timespan & All years \\
\hline Language & English \\
\hline Document Type & Peer-Reviewed, Full Text Articles \\
\hline Research Area & Business, Management, Economics \\
\hline Source & Academic Journals \\
\hline
\end{tabular}

First, the 50 articles retrieved from Scopus and WoS were scanned for duplicated titles using Mendeley which resulted in retaining 45 after removing 5 similar articles from both databases. Second, to ensure the quality of the articles included in the study, only articles from journals listed in the academic journal guide for Chartered Association of Business Schools (ABS) are included in the study (Paul \& Benito, 2018). Subsequently, 34 titles were identified eligible papers to be included in the systematic literature review. Finally, cross-referencing was used to identify additional papers relevant to the study, 9 new papers are identified and added after checking the scope of the topic, the inclusion and quality criteria. As a result, the refined final list consists of only 42 articles as illustrated below in Table 2.

Table 2 Distribution of Papers Selected from ABS Journals, Authors and Date of Publication

\begin{tabular}{|c|c|c|}
\hline Journal Title & Articles & Authors, Year \\
\hline Journal of Retailing and Consumer Services & 7 & $\begin{array}{l}\text { (Hollebeek et al., 2020; Huang, 2021; Javornik, 2016; Li } \\
\text { and Fang, 2020; Poncin and Ben Mimoun, 2014; Poush- } \\
\text { neh, 2018b; Poushneh and Vasquez-Parraga, 2017) }\end{array}$ \\
\hline Journal of Business Research & 5 & $\begin{array}{l}\text { (Brannon Barhorst et al., 2021a; Flavián et al., 2019a; Hudson et } \\
\text { al., 2019; Matarazzo et al., 2021; Sung, 2021) }\end{array}$ \\
\hline Tourism Management & 2 & (He et al., 2018; Park and Stangl, 2020b) \\
\hline Tourism Management Perspectives & 2 & (Cranmer et al., 2020; Hsu, 2018) \\
\hline Business Horizons & 2 & (de Regt et al., 2020a; Scholz and Smith, 2016) \\
\hline Journal of Interactive Marketing & 2 & (Kim and Forsythe, 2008; Yim et al., 2017) \\
\hline Internet Research & 2 & (Huang and Liao, 2017; Huang and Liu, 2014) \\
\hline Personal and Ubiquitous Computing & 2 & (Litvak and Kuflik, 2020; Olsson et al., 2013) \\
\hline Journal of Travel Research & 2 & (Chung et al., 2018; Tussyadiah et al., 2018) \\
\hline International Journal of Retail Distribution Management & 2 & (Pantano et al., 2018; Perannagari and Chakrabarti, 2019) \\
\hline International Journal of Contemporary Hospitality Management & 1 & (Milman et al., 2020) \\
\hline International Journal of Engineering Business Management & 1 & (Kounavis et al., 2012) \\
\hline Journal of Business Economics and Management & 1 & (Davidavičienė et al., 2021) \\
\hline Journal of Business \& Industrial Marketing & 1 & (Nussipova et al., 2019) \\
\hline Journal of Destination Marketing Management & 1 & (Marasco et al., 2018) \\
\hline Journal of Service Management & 1 & (Buhalis et al., 2019) \\
\hline Journal of Services Marketing & 1 & (Huang et al., 2019) \\
\hline Journal of Place Management and Development & 1 & (Jung and tom Dieck, 2017) \\
\hline Journal of the Academy of Marketing Science & 1 & (Hilken et al., 2017) \\
\hline Futures & 1 & (Kymäläinen, 2013) \\
\hline Qualitative Market Research & 1 & (Cuomo et al., 2020) \\
\hline Psychology and Marketing & 1 & (Rauschnabel, 2018) \\
\hline
\end{tabular}




\begin{tabular}{ccll}
\hline Journal Title & Articles & Authors, Year \\
\hline Technological Forecasting \& Social Change & 1 & (Rese, Baier, Geyer-Schulz, et al., 2017) \\
\hline ACM Transactions on Internet Technology & 1 & (Pascoal et al., 2020) \\
\hline & 42 & \\
\hline
\end{tabular}

It was depicted that few papers in the management \& business research area were published before 2017, an increase in the publications from 2017 to 2021 was noted. Yet, it can be concluded that the amount of research from business discipline is not comparable to the research published from both engineering and computer science disciplines. However, as it can be seen in Table 2, both the journal of retailing and consumer services, and the journal of business research contribute with the highest number of published papers $(n=12)$ addressing Augmented Reality issue to date.

\section{Data Extraction and Content Analysis}

Document analysis is qualitative and analytical procedure that focuses on synthesizing data contained in research articles to extract rich information, discover relevant patterns and relationships from the existing body of knowledge. Further, set direction for additional research questions and new conditions to be observed and investigated (Bowen, 2009). As result, this approach is useful in studies designed to explore and explain a concepts throughout recognizing emerging words, patterns and themes within the data that are selected and organized into codes and categories used for content analysis (Fereday and Muir-Cochrane, 2006).

The textual information in the articles screened and selected for the study purpose was examined using "WordStat 8", a content analysis software that includes numerous text mining and graphical tools that help exploring and extracting the content of articles. Accordingly, discover relationships between keywords, identification of the most recurring phrases, and clustering similar segments across articles. The process of content analysis involves conceptual analysis to quantify the frequency of concepts occurrence within sample cases analysed (i.e. peer-reviewed articles). Consequently, coding into a set of categories to examine and evaluate the relationships between concepts identified in the text to draw meaningful results and interpretations.

The visual word cloud (See Figure 1) gives a quick graphical representation of words frequencies depicted within the documents analysed, whereas the size of each word indicate the occurrence level in the text. Thus, providing a good starting point to highlight the concepts that appear frequently in the unstructured data.

Consequently, start analysing the data in order to extract meaningful information that uncover the hidden thematic structure of the text. Then, creating a categorization dictionary to group words or phrases, and exclude low frequency items prior to using topic modelling procedure (See Table 3). To differentiate documents and extract more precise results about the various topics they contain, an analysis at the documents level is conducted to segment the dominant issues contained across the 42 cases. The emergent themes were categorized into 6 broad topics as illustrated in Table 3.

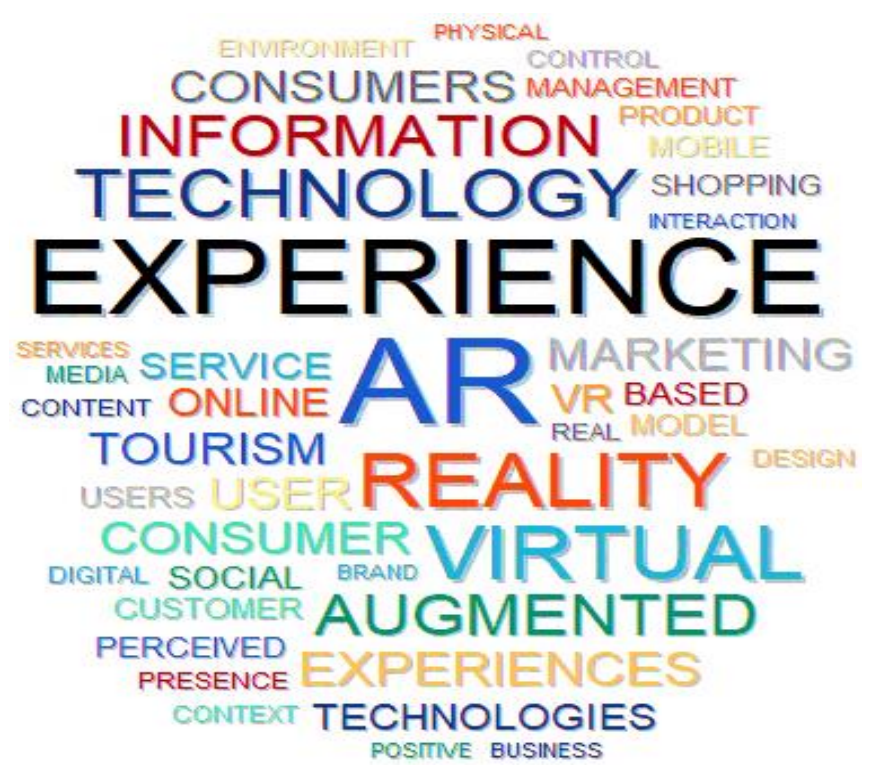

Figure 1 Visual Representation of Words Frequencies Using Cloud Graph 
Table 3 Topics Extracted from the Document Analysis

\begin{tabular}{|c|c|c|c|c|c|}
\hline Topics & Keywords & Coherence & Frequency & No. Cases & \%Cases \\
\hline $\begin{array}{l}\text { Immersive } \\
\text { Experience }\end{array}$ & $\begin{array}{l}\text { mental imagery; virtual presence; visual cues; verbal cues; dy- } \\
\text { namic cues; imagery process; design elements; information } \\
\text { type; aesthetic appreciation; imagery vividness; information } \\
\text { processing; augmenting immersive scenes; immersive experi- } \\
\text { ence; visitors willingness to pay. }\end{array}$ & 0.471 & 1681 & 42 & $100.00 \%$ \\
\hline $\begin{array}{l}\text { Interactive } \\
\text { Technology }\end{array}$ & $\begin{array}{l}\text { augmented reality (AR); virtual reality; smart glasses; robotic } \\
\text { functions; robotic qualities; technology-human interactions; } \\
\text { safety; service experience; playfulness feelings; positive influ- } \\
\text { ence; customer responses. }\end{array}$ & 0.449 & 1275 & 42 & $100.00 \%$ \\
\hline $\begin{array}{l}\text { Customer } \\
\text { Experience }\end{array}$ & $\begin{array}{l}\text { customer experience; online shopping; digital technologies; so- } \\
\text { cial media; shared social experience; brand experience; shopping } \\
\text { experience; social interaction; customer satisfaction; positive ef- } \\
\text { fect; service quality; purchase intentions; customer behaviour. }\end{array}$ & 0.436 & 1227 & 41 & $97.67 \%$ \\
\hline $\begin{array}{l}\text { Ownership } \\
\text { Control \& } \\
\text { Surveillance }\end{array}$ & $\begin{array}{l}\text { physiological state; sense of ownership control; body surveil- } \\
\text { lance; consciousness; haptic imagery; explorative engagement; } \\
\text { flow experience; rapport experience; online service experience; } \\
\text { decision making; utilitarian and hedonic value perceptions. }\end{array}$ & 0.418 & 1050 & 40 & $95.35 \%$ \\
\hline $\begin{array}{l}\text { Virtual Real } \\
\text { Environ- } \\
\text { ment }\end{array}$ & $\begin{array}{l}\text { virtual world; virtual objects; physical world; mixed reality; real } \\
\text { world; real time; augmented reality (AR) technology; smart } \\
\text { glasses; smart retailing; smartphones; mobile AR applications. }\end{array}$ & 0.372 & 1064 & 41 & $97.67 \%$ \\
\hline $\begin{array}{l}\text { User Accep- } \\
\text { tance }\end{array}$ & $\begin{array}{l}\text { technology acceptance; perceived usefulness; perceived ease of } \\
\text { use; perceived enjoyment; user acceptance of information tech- } \\
\text { nology; technology anxiety; attitude towards augmented reality. }\end{array}$ & 0.364 & 933 & 40 & $95.35 \%$ \\
\hline
\end{tabular}

To further explore the connections between concepts, an average-linkage hierarchical cluster analysis and multidimensional scaling mapping methods are used to create clusters from a similarity matrix. Keywords that tend to appear together are combined into categories, the results are visually presented in the form tree diagram called Dendrogram (See Figure 2) and multidimensional concept map (See Figure 3) to depict a group of interrelated co-occurring concepts representing the overall meaning of the explicit concepts extracted from the unstructured data and its relationships.

\section{Findings and Discussion}

The digitalization wave has given birth to "Smart Technologies" and draws attention towards exploring related issues to this concept rather than merely focusing on the technical aspects of these technologies. Smart technologies enabled intelligent use of data to deliver pro-active, personalised, adaptable services whereas customers are always the co-creators of value.

It is recognised that AR is a smart technology that creates value for customers (Dacko, 2017). In con $\epsilon$ trast to other smart technologies (i.e. RFID; self-services; mobile wallets;) that help customers to save time and effort during task performance, AR is an interactive offline-online technology that empowers customers to actively co-create their individualised smart service experience. The customer interacts with smart technology and participates in service co-creation which is a typical example of smart service encounter (Huang, 2018).

It was evident from the stream of research, that most of researchers' have a clear interest in exploring the interactive nature of Augmented Reality (AR) as new digital technology and defining its experiential characteristics that will affect customers' perceptions of service operations. Hence, in line with these findings, and grounded on the service literature body of knowledge, Augmented Reality can be defined as: "smart service based technology that generate value-in-use experiences". 


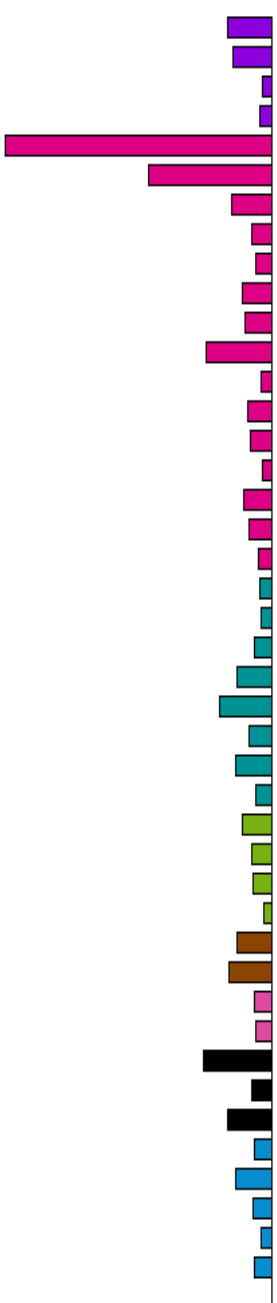

9 SINGLE WORD CLUSTERS REMOVED

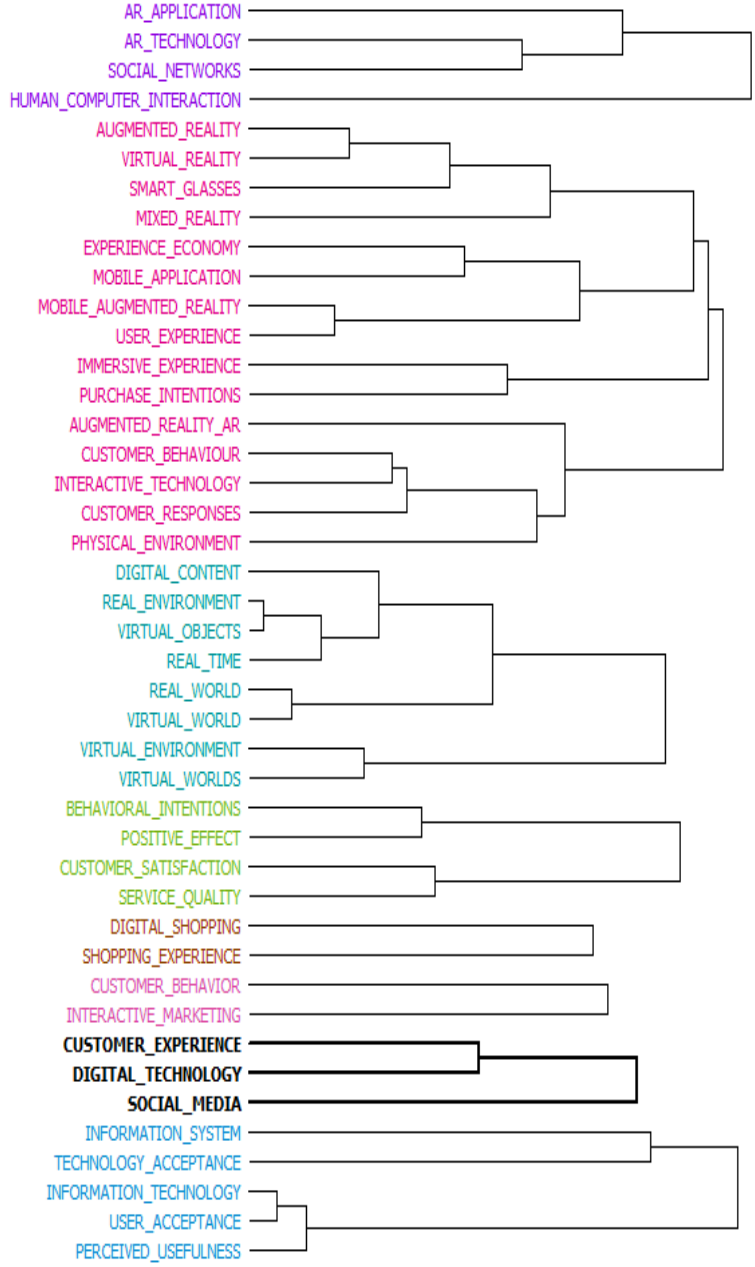

AGGLOMERATION ORDER: ASSOCIATION STRENGTH (OCCURRENCE)

Figure 2 Cluster Analysis - Dendrogram

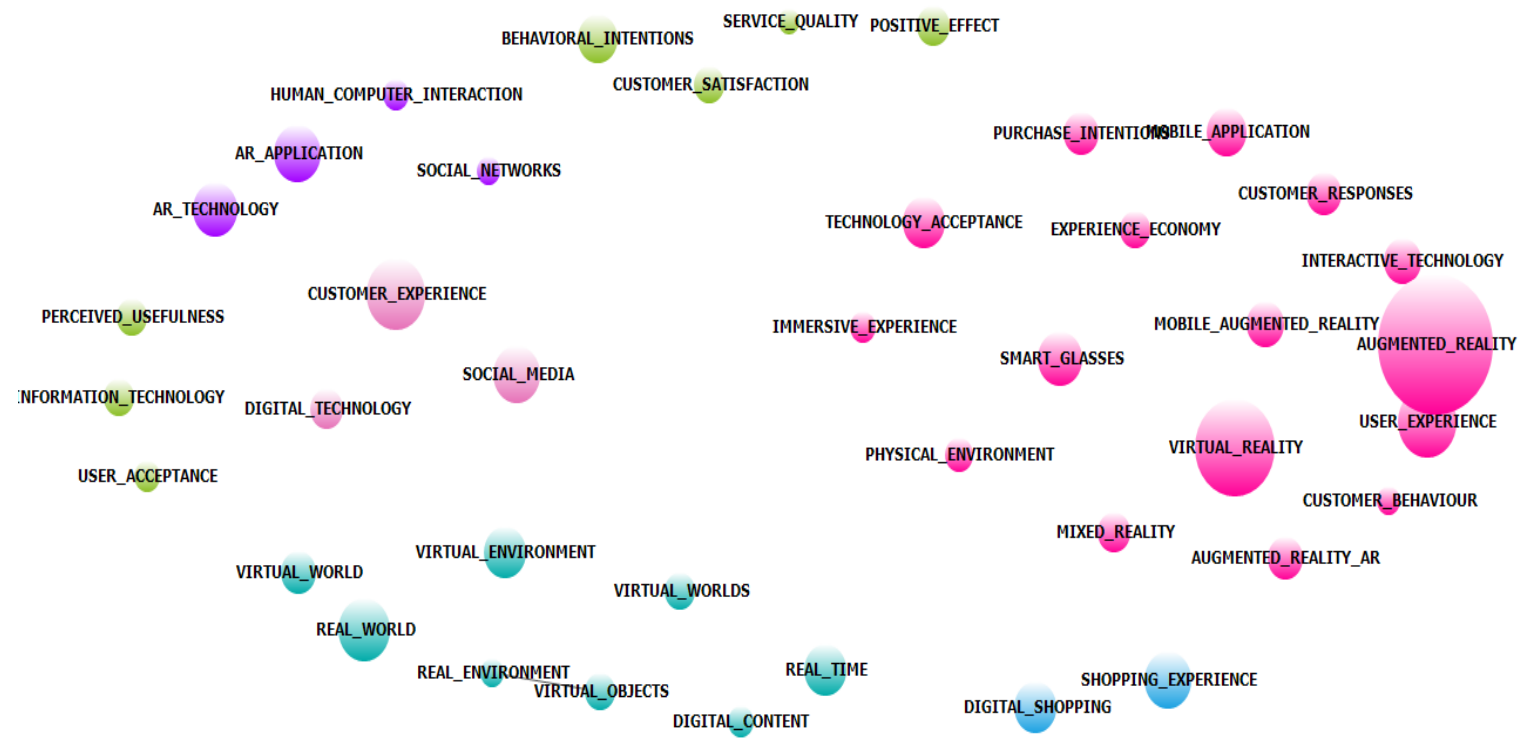

Figure 3 Multidimensional Concept Map 


\section{Augmented Reality (AR): Smart Service Based Technology}

AR is a human-computer interaction technology that combines reality with virtual reality by applying computer-generated virtual information into physical world. AR is an intelligent display technology using either video-through or see-through devices, with accurate tracking 3D registration and variety of intelligent interactions in real-time between users and virtual objects within real contexts (Brannon Barhorst et al., 2021b).

AR-based technologies consist of two categories with recognition features that enable the reproduction of augmented information without restrictions of place and time. The first, image-based which is a marker-based AR that recognizes artificial labels and visual tags. The second, location-based which is marker-less AR that uses position data through GPS or wireless network as recognition method (Tsai, 2013).

AR uses digital devices to overlay virtual elements on the real world which stimulates users' multi-sensory involvement, permits three-dimensional and social interactions experience, as well as enabling users to have dynamic adjustments while viewing, trying and using objects. (Wedel et al., 2020). Accordingly, these AR features can allow customers to get access to real-time and adaptable virtual information that is integrated into their actual surroundings to create a complete sense of real presence experience (Park and Stangl, 2020a).

It is denoted that AR main characteristics are categorised into: (1) degree of interaction with virtual and physical contexts, thus stimulates multisensory effects, called "immersion" which creates highly vivid experience that affect the degree of realism perceived within AR environment; (2) processing quality refers to the reliability, promptness, responsiveness of requested services that allow users to edit and modify transmitted digital content within AR context quickly, efficiently and effectively; (3) visualisation quality is concerned with the quality of media content combined with the quality of digital devices presenting content; (4) information quality relates to the amount of information provided and information quality, in terms of its accuracy, completeness, availability, retrievablity, accessibility and relevance to the context in which it is intended to be used in; (5) personal information handling that derives users' concerns about security assurance, privacy protection and control (Kowalczuk et al., 2021).

It is confirmed that customers will cognitively, affectively and behaviourally respond to AR service encounters that have key features aligned with AR characteristics and that gratify value-in-use experiences. Therefore, it can be concluded that AR is considered a smart service based technology characterized by offering customers with real vivid stimulation experiences that allow them to control and modify sensory stimulations (Huang, 2018).

\section{Augmented Reality (AR) Technology Value-in-Use}

Drawing on S-D logic approach, organisations recognize that value is created in use and specific to a context, thus varies for each customer. The key characteristics of value-in-use consist of the customers' active role in value creation, aligned with their context-specific goals' achievement. This means that value can only be determined by the customers. Therefore, it is suggested that value-in-use can be understood by the perceived consequences arising from AR usage process. Accordingly, it is noted that value-in-use is defined by customers' evaluation of AR consumption experiences that evolve over time and can be positive or negative. (Schwipper et al., 2020; Font et al., 2021).

Holbrook (2006), states that value resides only in experience, which implies that AR value-in-use has experience-based characteristics that can be refined based on value typologies (Gallarza et al., 2017). Expee riential value can be viewed with respect to Holbrook's typology of consumer's value encompassing three continuous dimensions ( 1 ) intrinsic and extrinsic benefits; (2) reactive and active activities; (3) self and oth- 
ers orientation, that were used to categorise value into four main groups including: economic, hedonic, social and altruistic. Yet, Holbrook value typology is not exhaustive, instead it can be used as guidance to explore new additional value types (Stewart Loane et al., 2015). The experiential values are gratifications resulting from sensory attributes of the overall perceived experience either through direct or indirect interactions with products/services (Tandon et al., 2014). Therefore, seamless sequence of cognitive, affective and physical responses resulting from human-technology interactions facilitated by AR technologies are key components for value-in-use experiences that can occur through direct or indirect participation of users in activities within AR context (Brannon Barhorst et al., 2021b).

\section{Augmented Reality (AR) Technology Generated Experiences}

Nowadays, reality-virtual technologies have redefined customer experience, taking into consideration that different technologies can directly or indirectly support "core experiences" by adding value to the customer journey stages, thus creating integral technology-enhanced experiences. On the other hand, "empowered experiences" resulting from the vital role technology plays will also generate new experiences either related or unrelated to customers' core experiences (Flavián et al., 2019b).

Yet to date, it was determined the scarcity of attempts to identify users' experiences with AR. Two main research streams related to users' expectations from AR were acknowledged. The first category was mainly concerned with studying AR experiences characteristics including utility, pragmatic, hedonic and emotional aspects. The second category focused on discussing the design requirements that facilitate the delivery of interactive experiences (Park and Stangl, 2020a).

It was mentioned that AR active experience is created and influenced by several factors including: virtual AR content; users' participation; and targets in the physical world (i.e. objects, ambient conditions) that are augmented. While AR passive experience encompasses non-participative users who just observe other users actions or view generated augmented content, and non-augmented targets (Scholz and Smith, 2016).

Thus, AR provides a combined view of digital and physical world by embedding realistic digital content into users' perceptions. Yet, it is argued that AR is not merely a technology, rather it is self-service quality enabler that achieves customizable value outcomes for customers through interactive, immersive, real-time and multi-sensory experiences induced by virtual media content (Heller et al., 2021; de Regt et al., 2020b) As a result, conventional services' operations are transformed into smart ones, creating an entirely different customer experience concept that can be labelled with "Smart Experience" (Kabadayi et al., 2019).

\section{Future Research Directions}

This study responds to calls for research about Augmented Reality (AR) to better understand how it can effectively transform service operations. The study synthesizes existing literature and summarizes the most valuable findings of the discussed topic. This review extracted and analysed the most important AR emerging themes in research to date. Yet, there is still a need for further academic research to investigate these trends, in order to provide academia and practitioners with the information necessary to enhance their service operations. It is evident that Augmented Reality (AR) technologies give users instant access to real-time information compiled with audio-visual media content through numerous sources, thus provide personalised experience and enhance the quality of service operations.

Given the interdisciplinary nature of service operations research, the identified key themes can be discussed from different disciplines (i.e. marketing, human resources, information systems, technology \& innovation, psychology, sociology, engineering...etc.) to instil new insights into future business and management research. Acknowledging the fact that AR is an interactive technology, human-technology interac- 
tions increased and replaced human interactions within a service encounter as well as workplace. Involving people in the production and delivery of services is a distinguishing feature of Augmented Reality (AR), Thus, it is crucial to further study the role of customers and employees in co-production and co-creation of operations and its effect on service performance. Moreover, to date, most of the research is focusing on technology acceptance theories that study people behaviours and attitudes, no clear framework or approach has been yet developed to study how technology-based interactive service operations are designed, managed and controlled to measure service operations performance.

It is clear that technology advances have driven the creation of service ecosystems where, customers are key actors in value co-creation throughout integrating required resources. Thus, it is essential to further investigate the uncertainty and variability emerging the actors' roles in new service ecosystems. Thus, requires studies about appropriate network structures and configuration to create value from information exchanged in real time to deliver customisable service operations and create new experiences. Consequently, rethinking the quality characteristics of interactive service operations and experiences generated has become a fertile research area, whereas a review and update of the existing service quality body of knowledge is necessary to accommodate the developments of new technology-based operations. 


\section{References}

Bani-Hani, I.; Pareigis, J.; Tona, O. and Carlsson, S. (2018). “A Holistic View of Value Generation Process In A SSBI Environment: A Service Dominant Logic Perspective", Journal of Decision Systems, Taylor \& Francis, Vol. 27, No. sup1, pp. 46-55.

- Bowen, G. A. (2009). “Document Analysis as a Qualitative Research Method”, Qualitative Research Journal, Vol. 9, No. 2, pp. 27-40.

- $\quad$ Brannon Barhorst, J.; McLean, G.; Shah, E. and Mack, R. (2021a). “Blending The Real World And The Virtual World: Exploring the Role of Flow In Augmented Reality Experiences", Journal of Business Research, Elsevier, Vol. 122, No. January, pp. 423-436.

- Brannon Barhorst, J.; McLean, G.; Shah, E. and Mack, R. (2021b). “BlendingtThe Real World and the Virtual World: Exploring the Role of Flow in Augmented Reality Experiences", Journal of Business Research, Elsevier, Vol. 122, No. August 2020, pp. 423-436.

- $\quad$ Buhalis, D.; Harwood, T.; Bogicevic, V.; Viglia, G.; Beldona, S. and Hofacker, C. (2019). "Technological Disruptions In Services: Lessons From Tourism and Hospitality", Journal of Service Management, Vol. 30, No. 4, pp. 484-506.

- Caboni, F. and Hagberg, J. (2019). "Augmented Reality in Retailing: A Review of Features, Applications and Value", International Journal of Retail and Distribution Management, Vol. 47, No. 11, pp. 1125-1140.

- Cavalinhos, S.; Marques, S. H. and Fátima Salgueiro, M. (2021). “The Use of Mobile Devices in-Store and the Effect on Shopping Experience: A Systematic Literature Review and Research Agenda", International Journal of Consumer Studies, No. March, p. ijcs.12690.

- $\quad$ Chung, N.; Lee, H.; Kim, J. Y. and Koo, C. (2018). "The Role of Augmented Reality For Experience-influenced Environments: The Case of Cultural Heritage Tourism in Korea", Journal of Travel Research, Vol. 57, No. 5, pp. 627-643.

- $\quad$ Chylinski, M.; Heller, J.; Hilken, T.; Keeling, D. I.; Mahr, D. and de Ruyter, K. (2020). "Augmented Reality Marketing: A Technology-enabled Approach to Situated Customer Experience", Australasian Marketing Journal, Elsevier Ltd, Vol. 28, No. 4, pp. 374-384.

- Cipresso, P.; Giglioli, I. A. C.; Raya, M. A. and Riva, G. (2018). “The Past, Present and Future of Virtual and Augmented Reality Research: A Network and Cluster Analysis of the Literature", Frontiers in Psychology, Vol. 9, pp. 1-20.

- Cranmer, E. E.; Tom Dieck, M. C. and Fountoulaki, P. (2020). “Exploring the Value of Augmented Reality For Tourism", Tourism Management Perspectives, Elsevier, Vol. 35 No. March, p. 100672.

- Cuomo, M. T.; Tortora, D.; Festa, G.; Ceruti, F. and Metallo, G. (2020). “Managing Omni-Customer Brand Experience Via Augmented Reality", Qualitative Market Research: An International/ournal, Vol. 23, No. 3, pp. 427-445.

- Dacko, S. G. (2017). “Enabling Smart Retail Settings Via Mobile Augmented Reality Shopping Apps", Technological Forecasting and Social Change, Elsevier Inc., Vol. 124, pp. 243-256.

- Davidavičienė, V.; Raudeliūnienè, J. and Viršilaitė, R. (2021). “Evaluation of User Experience in Augmented Reality Mobile Applications", Journal of Business Economics and Management, Vol. 22 No. 2, pp. 467-481.

- de Regt, A.; Barnes, S. J. and Plangger, K. (2020a). "The Virtual Reality Value Chain", Business Horizons, Elsevier Ltd, Vol. 63, No. 6, pp. 737-748.

- de Regt, A.; Barnes, S. J. and Plangger, K. (2020b). "The Virtual Reality Value Chain", Business Horizons, Elsevier Ltd., Vol. 63, No. 6, pp. 737-748. 
Fereday, J. and Muir-Cochrane, E. (2006). “Demonstrating Rigor Using Thematic Analysis: A Hybrid Approach of Inductive and Deductive Coding and Theme Development", International Journal of Qualitative Methods, Vol. 5, No. 1, pp. 80-92.

Flavián, C.; Ibáñez-Sánchez, S. and Orús, C. (2019a). "The Impact of Virtual, Augmented and Mixed Reality Technologies on the Customer Experience", Journal of Business Research, Elsevier, Vol. 100, No. July, pp. 547-560.

- $\quad$ Flavián, C.; Ibáñez-Sánchez, S. and Orús, C. (2019b). “The Impact of Virtual, Augmented and Mixed Reality Technologies on the Customer Experience", Journal of Business Research, Vol. 100, pp. 547-560. Font, X.; English, R.; Gkritzali, A. and Tian, W. (Stella). (2021). "Value Co-creation in Sustainable Tourism: A Service-Dominant Logic Approach", Tourism Management, Vol. 82, No. February, p. 104200. Gallarza, M. G.; Arteaga, F.; Del Chiappa, G.; Gil-Saura, I. and Holbrook, M. B. (2017). "A Multidimensional Service-Value Scale Based on Holbrook's Typology of Customer Value: Bridging the Gap between the Concept and its Measurement", Journal of Service Management, Vol. 28, No. 4, pp. 724-762.

- Gusenbauer, M. and Haddaway, N. R. (2020). "Which Academic Search Systems are Suitable for Systematic Reviews or Meta-analyses? Evaluating Retrieval Qualities of Google Scholar, PubMed, And 26 Other Resources", Research Synthesis Methods, Vol. 11, No. 2, pp. 181-217.

He, Z.; Wu, L. and Li, X. (Robert). (2018). "When Art Meets Tech: The Role of Augmented Reality in Enhancing Museum Experiences and Purchase Intentions", Tourism Management, Elsevier Ltd., Vol. 68, No. October, pp. 127-139.

- Heller, J.; Chylinski, M.; de Ruyter, K.; Keeling, D. I.; Hilken, T. and Mahr, D. (2021). “Tangible Service Automation: Decomposing the Technology-enabled Engagement Process (TEEP) for Augmented Reality", Journal of Service Research, Vol. 24, No. 1, pp. 84-103.

- $\quad$ Hilken, T.; de Ruyter, K.; Chylinski, M.; Mahr, D. and Keeling, D. I. (2017). “Augmenting the Eye of the Beholder: Exploring the Strategic Potential of Augmented Reality to Enhance Online Service Experiences", Journal of the Academy of Marketing Science, Vol. 45, No. 6, pp. 884-905.

- Hilken, T.; Heller, J.; Chylinski, M.; Keeling, D. I.; Mahr, D. and de Ruyter, K. (2018). “Making Omnichannel an Augmented Reality: The Current and Future State of the Art", Journal of Research in Interactive Marketing, Vol. 12, No. 4, pp. 509-523.

- Hollebeek, L. D.; Clark, M. K.; Andreassen, T. W.; Sigurdsson, V. and Smith, D. (2020), “Virtual Reality Through the Customer Journey: Framework and Propositions", Journal of Retailing and Consumer Services, Elsevier Ltd, Vol. 55 No. January, p. 102056.

- Hoyer, W. D.; Kroschke, M.; Schmitt, B.; Kraume, K. and Shankar, V. (2020). “Transforming the Customer Experience Through New Technologies", Journal of Interactive Marketing, Elsevier Inc., Vol. 51, pp. 57-71.

- Hsu, C. H. C. (2018). "Tourism Education on and Beyond the Horizon", Tourism Management Perspectives, Elsevier, Vol. 25, No. January, pp. 181-183.

- Huang, T. L. (2018). “Creating A Commercially Compelling Smart Service Encounter”, Service Business, Springer Berlin Heidelberg, Vol. 12, No. 2, pp. 357-377.

Huang, T. L. (2021). “Restorative Experiences and Online Tourists' Willingness to Pay a Price Premium in an Augmented Reality Environment", Journal of Retailing and Consumer Services, Elsevier Ltd., Vol. 58, No. January, p. 102256.

- Huang, T. L.; Mathews, S. and Chou, C.Y. (2019). “Enhancing Online Rapport Experience Via Augmented Reality", Journal of Services Marketing, Vol. 33, No. 7, pp. 851-865.

- Huang, T. L. and Liao, S. L. (2017). “Creating E-shopping Multisensory Flow Experience Through Augmented-reality Interactive Technology", Internet Research, Vol. 27, No. 2, pp. 449-475. 
Huang, T. L. and Liu, F. H. (2014). “Formation of Augmented-Reality Interactive Technology's Persuasive Effects from the Perspective of Experiential Value", Internet Research, Vol. 24, No. 1, pp. 82-109. Hudson, S.; Matson-Barkat, S.; Pallamin, N. and Jegou, G. (2019). “With or Without You? Interaction and Immersion in a Virtual Reality Experience", Journal of Business Research, Vol. 100, No. July, pp. 459-468.

- Javornik, A. (2016). “Augmented Reality: Research Agenda for Studying the Impact of its Media Characteristics on Consumer Behaviour", Journal of Retailing and Consumer Services, Elsevier, Vol. 30, pp. 252-261.

- Jung, T. H. and Tom Dieck, M. C. (2017). "Augmented Reality, Virtual Reality and 3D Printing for the Co-creation of Value for the Visitor Experience at Cultural Heritage Places", Journal of Place Management and Development, Vol. 10, No. 2, pp. 140-151.

- Kabadayi, S.; Ali, F.; Choi, H.; Joosten, H. and Lu, C. (2019). "Smart Service Experience in Hospitality and Tourism Services: A Conceptualization and Future Research Agenda", Journal of Service Management, Vol. 30, No. 3, pp. 326-348.

- $\quad$ Kim, J. and Forsythe, S. (2008). "Adoption of Virtual Try-on Technology for Online Apparel Shopping", Journal of Interactive Marketing, Elsevier, Vol. 22, No. 2, pp. 45-59.

Kounavis, C. D., Kasimati; A. E. and Zamani, E. D. (2012). “Enhancing the Tourism Experience Through Mobile Augmented Reality: Challenges and Prospects", International Journal of Engineering Business Management, Vol. 4, No. 1, pp. 1-6.

- Kowalczuk, P.. Siepmann (née Scheiben), C. and Adler, J. (2021), “Cognitive, Affective and Behavioral Consumer Responses to Augmented Reality in E-commerce: A Comparative Study", Journal of Business Research, Vol. 124, No. January, pp. 357-373.

- Kymäläinen, T. (2013). “Dreamnesting - Co-created Future Vision of an Intelligent Interior Design Experience", Futures, Vol. 50, No. June, pp. 74-85.

- $\quad$ Li, C. Y. and Fang, Y. H. (2020). "I Searched, I Collected, I Experienced: Exploring How Mobile Augmented Reality Makes the Players Go", Journal of Retailing and Consumer Services, Elsevier Ltd., Vol. 54, No. 151, p. 102018.

- $\quad$ Lindhult, E.; Chirumalla, K.; Oghazi, P. and Parida, V. (2018). “Value Logics For Service Innovation: Practice-driven Implications for Service-dominant Logic", Service Business, Springer Berlin Heidelberg, Vol. 12, No. 3, pp. 457-481.

- $\quad$ Litvak, E. and Kuflik, T. (2020). “Enhancing Cultural Heritage Outdoor Experience With Augmented-Reality Smart Glasses", Personal and Ubiquitous Computing, Personal and Ubiquitous Computing, Vol. 24, No. 6, pp. 873-886.

- Marasco, A.; Buonincontri, P.; van Niekerk, M.; Orlowski, M. and Okumus, F. (2018). “Exploring The Role of Next-Generation Virtual Technologies in Destination Marketing", Journal of Destination Marketing \& Management, Elsevier Ltd., Vol. 9, No. September, pp. 138-148.

- Matarazzo, M.; Penco, L.; Profumo, G. and Quaglia, R. (2021). “Digital Transformation and Customer Value Creation in Made in Italy SMEs: A Dynamic Capabilities Perspective", Journal of Business Research, Elsevier Inc., Vol. 123, No. February, pp. 642-656.

- Milman, A.; Tasci, A. and Zhang, T. (2020). “Perceived Robotic Server Qualities and Functions Explaining Customer Loyalty in the Theme Park Context", International Journal of Contemporary Hospitality Management, Vol. 32, No. 12, pp. 3895-3923.

- Nussipova, G.; Nordin, F. and Sörhammar, D. (2019). “Value Formation With Immersive Technologies: An Activity Perspective", Journal of Business \& Industrial Marketing, Vol. 35, No. 3, pp. 483-494. 
Olsson, T.; Lagerstam, E.; Kärkkäinen, T. and Väänänen-Vainio-Mattila, K. (2013), “Expected User Experience Of Mobile Augmented Reality Services: A User Study in the Context of Shopping Centres", Personal and Ubiquitous Computing, Vol. 17, No. 2, pp. 287-304.

Pantano, E.; Priporas, C.V. and Dennis, C. (2018). "A New Approach To Retailing For Successful Competition in the New Smart Scenario", International Journal of Retail \& Distribution Management, Vol. 46, No. 3, pp. 264-282.

Park, S. and Stangl, B. (2020a). "Augmented Reality Experiences and Sensation Seeking", Tourism Management, Elsevier Ltd, Vol. 77, No. November 2019, p. 104023.

Park, S. and Stangl, B. (2020b). "Augmented Reality Experiences and Sensation Seeking", Tourism Management, Elsevier Ltd, Vol. 77, No. February, p. 104023.

Pascoal, R.; Almeida, A. De and Sofia, R. C. (2020). "Mobile Pervasive Augmented Reality Systems MPARS: The Role of User Preferences in the Perceived Quality of Experience in Outdoor Applications", ACM Transactions on Internet Technology, Vol. 20, No. 1, pp. 1-17.

- Perannagari, K. T. and Chakrabarti, S. (2019). "Factors Influencing Acceptance of Augmented Reality In Retail: Insights from Thematic Analysis", International Journal of Retail and Distribution Management, Vol. 48, No. 1, pp. 18-34.

- Poncin, I. and Ben Mimoun, M. S. (2014). "The Impact of E-Atmospherics on Physical Stores", Journal of Retailing and Consumer Services, Elsevier, Vol. 21, No. 5, pp. 851-859.

- Poushneh, A. (2018a). "Augmented Reality in Retail : A Trade-off between User's Control of Access to Personal Information and Augmentation Quality", Journal of Retailing and Consumer Services, Elsevier Ltd, Vol. 41, pp. 169-176.

Poushneh, A. and Vasquez-parraga, A.Z. (2017). "Customer Dissatisfaction and Satisfaction With Augmented Reality in Shopping And Entertainment", Journal of Consumer Satisfaction, Dissatisfaction and Complaining Behavior, Vol. 30, pp. 97-118.

- Poushneh, A. and Vasquez-Parraga, A. Z. (2017). “Discernible Impact of Augmented Reality on Retail Customer's Experience, Satisfaction and Willingness to Buy", Journal of Retailing and Consumer Services, Elsevier, Vol. 34, No. January, pp. 229-234.

- $\quad$ Rauschnabel, P. A. (2018). “Virtually Enhancing the Real World With Holograms: An Exploration of Expected Gratifications of Using Augmented Reality Smart Glasses", Psychology and Marketing, Vol. 35, No. 8, pp. 557-572.

- $\quad$ Rese, A.; Baier, D.; Geyer-Schulz, A. and Schreiber, S. (2017). “How Augmented Reality Apps are Accepted by Consumers: A Comparative Analysis Using Scales and Opinions", Technological Forecasting and Social Change, Elsevier Inc., Vol. 124, pp. 306-319.

- $\quad$ Rese, A.; Baier, D.; Geyer-schulz, A. and Schreiber, S. (2017). “Technological Forecasting \& Social Change How Augmented Reality Apps Are Accepted By Consumers: A Comparative Analysis Using Scales And Opinions", Technological Forecasting \& Social Change, Elsevier Inc., Vol. 124, pp. 306319.

- $\quad$ Roxo, M. T. and Brito, P.Q. (2018). "Augmented Reality Trends to the Field of Business and Economics: A Review of 20 Years of Research", Asia Journal of Business Research, Vol. 8, No. 2, pp. 94-117.

- Scholz, J. and Duffy, K. (2018). “We are at Home: How Augmented Reality Reshapes Mobile Marketing and Consumer-Brand Relationships", Journal of Retailing and Consumer Services, Vol. 44, No. September, pp. 11-23.

Scholz, J. and Smith, A.N. (2016). "Augmented Reality: Designing Immersive Experiences That Maximize Consumer Engagement", Business Horizons, "Kelley School of Business, Indiana University", Vol. 59, No. 2, pp. 149-161. 
Schwipper, S.; Peche, S. and Schmitz, G. (2020). “Mobile Location-based Services' Value-in-Use in Inner Cities: Do a Customer's Shopping Patterns, Prior User Experience and Sales Promotions Matter?", Schmalenbach Business Review, Vol. 72, No. 4, pp. 511-564.

- Shankar, V.; Kalyanam, K.; Setia, P.; Golmohammadi, A.; Tirunillai, S.; Douglass, T.; Hennessey, J. et al. (2021). “How Technology Is Changing Retail”, Journal of Retailing, Vol. 97, No. 1, pp. 13-27.

- Stewart Loane, S.; Webster, C. M. and D’Alessandro, S. (2015). “Identifying Consumer Value Co-created Through Social Support Within Online Health Communities", Journal of Macromarketing, Vol. 35, No. 3, pp. 353-367.

- $\quad$ Sung, E. (Christine). (2021). "The Effects of Augmented Reality Mobile App Advertising: Viral Marketing Via Shared Social Experience", Journal of Business Research, Elsevier, Vol. 122, No. January, pp. $75-87$.

- $\quad$ Tandon, A.; Tripathi, V. and Gupta, A. (2014). "The Transformation of Value and Evolution of Customer Experience: An Exploration of The Typologies, Facets and Significance", International Journal of Indian Culture and Business Management, Vol. 8, No. 4, p. 425.

- Tsai, K. C. C. (2013). "Affordances of Augmented Reality in Science Learning: Suggestions for Future Research", Journal of Science Education and Technology, Vol. 22, pp. 449-462.

- Tussyadiah, I. P.; Jung, T. H. and Tom Dieck, M. C. (2018). "Embodiment of Wearable Augmented Reality Technology in Tourism Experiences", Journal of Travel Research, Vol. 57, No. 5, pp. 597-611.

- Watson, A.; Alexander, B. and Salavati, L. (2020). “The Impact of Experiential Augmented Reality Applications on Fashion Purchase Intention", International Journal of Retail and Distribution Management, Vol. 48, No. 5, pp. 433-451.

- Wedel, M.; Bigné, E. and Zhang, J. (2020). “Virtual and Augmented Reality: Advancing Research in Consumer Marketing", International Journal of Research in Marketing, Elsevier B. V., Vol. 37, No. 3, pp. 443-465.

- Yim, M.; Y. C.; Chu, S. C. and Sauer, P. L. (2017). “Is Augmented Reality Technology an Effective Tool for E-commerce? An Interactivity and Vividness Perspective", Journal of Interactive Marketing, Direct Marketing Educational Foundation, Inc. dba Marketing EDGE, Vol. 39, pp. 89-103.

- Yussof, F. M.; Salleh, S. M. and Ahmad, A. L. (2019). "Augmented Reality: A Systematic Literature Review and Prospects for Future Research in Marketing and Advertising Communication", Lecture Notes in Networks and Systems, Vol. 67, pp. 459-473. 
